\title{
As políticas de formação e a crise da profissionalização docente: por onde passa a valorização?
}

Teacher education policies and the crisis of teacher professionalization: to where the valorization is going?

\author{
Dalila Andrade Oliveira \\ Universidade Federal de Minas Gerais
}

\section{Resumo}

A busca pela compreensão dos fatores que levam à melhoria da educação tem levado certas abordagens a colocar o professor como o principal responsável pela tarefa educativa e, consequentemente, por seus resultados, deslocando o foco das estruturas e das relações sociais que envolvem o contexto escolar. As políticas educacionais na atualidade refletem essa preocupação ao situar o docente no centro do debate. Há um sentimento generalizado de que a profissão docente sofre um processo de desvalorização. A instituição da Lei do Piso Salarial Profissional Nacional e a criação do PARFOR são algumas das políticas orientadas na direção de maior valorização docente. A preocupação em articular políticas de formação às condições de profissionalização é resultante do acentuado peso dado à formação na definição e certificação da profissão. Este texto, baseando-se em dados de pesquisa, procura discutir algumas correlações entre formação inicial e formação continuada com a remuneração, na tentativa de evidenciar seus nexos para maior valorização docente.

Palavras-chave: Formação docente. Políticas de formação. Desenvolvimento profissional docente. Profissão docente.

\section{Abstract}

Trying to understand some factors that can improve quality in education, certain theoretical approaches indicate teachers as the main focus in the schooling process, hence, for its outcomes, displacing the main focus from social relations and structure. Current educational policies reflect this point of view when put teachers as a central issue of the education debate. There is a widespread feeling that teachers are under a professional devaluation. The Act for a National Professional Minimum Salary and the PARFOR - National Teacher Education Program for Basic Education - are some policies toward to increase teacher valorization. This concern in articulating teacher education policies with professional working conditions is result of the emphasis in education for teacher certification. This paper, based on empirical data, aims at discussing some correlations between initial and continuing education and remuneration, in order to better understand their connections to greater teacher valorization.

Keywords: Teacher Education. Teacher Education Policies. Teacher Professional Developing. Teacher Profession. 
A valorização dos profissionais da educação é um tema cada vez mais presente no debate educacional brasileiro. As condições às quais são submetidos os profissionais da educação nas distintas redes públicas de ensino no país têm sido objeto de preocupação da sociedade. Os baixos salários, a falta de perspectiva na carreira, a carga de trabalho e problemas de infraestrutura que afetam diretamente a prática docente são apontados como fatores preocupantes por pesquisas acadêmicas, pelos sindicatos, pela imprensa e pela sociedade em geral. Existe certo consenso de que a profissão docente, referindo-se aos profissionais que atuam na educação básica, sofre um processo de desvalorização há décadas, sendo que a condição desses profissionais é muito variável no país, dependendo da rede em que são contratados, da etapa de ensino em que atuam e até mesmo da formação que receberam.

termo valorização docente reúne três importantes elementos que interferem na sua condição profissional, são eles: 1) a remuneração; 2) a carreira e condições de trabalho e 3) a formação inicial e continuada.

A instituição do Piso Salarial Profissional Nacional (PSPN), por meio da Lei $n^{\circ} 11.738$ de 16 de julho de 2008, representou um importante passo na conquista de maior valorização dos profissionais da educação básica 52 no país. Após décadas de lutas, a determinação legal obrigando os municípios e estados brasileiros a cumprirem a exigência de um patamar mínimo de remuneração aos docentes ${ }^{4}$ representou grande avanço no sentido de se alcançar maior equilíbrio e isonomia entre as redes. Ainda que o valor esteja muito abaixo do necessário para garantir uma vida digna aos docentes de educação básica, considerando, sobretudo, que o Piso está definido para os que possuem normal médio e que cumprem jornada de 40 horas de trabalho semanais, a instituição do PSPN representa passo decisivo no reconhecimento destes como profissionais que desempenham importante papel na sociedade brasileira. O PSPN obriga os 26 estados da federação e o Distrito Federal, bem como os 5.564 municípios, a pagarem o mesmo valor e oferecer condições similares de trabalho, contratação por 40 horas e a destinação do limite máximo de dois terços da carga horária para o desempenho de atividades de interação com os educandos, devendo um terço ser dedicado a atividades extraclasse. A instituição do PSPN deveria ainda ser considerada como um reforço à carreira profissional, enfraquecida em decorrência da degradação sofrida pelas condições de trabalho nas redes públicas estaduais e municipais nas últimas décadas do século passado no país e ainda persistentes na 
atualidade. Entretanto, a exigência do cumprimento da Lei do Piso tem representado em muitas redes direção contrária, ou seja, observa-se por parte de algumas gestões estaduais e municipais o desenvolvimento de estratégias que visam a diminuir as possibilidades de promoção ou mesmo a incorporação de outros ganhos aos salários, o que pode levar ao achatamento e corrosão da carreira.

A pesquisa acadêmica evidencia o processo de degradação das carreiras e condições de trabalho por meio de resultados de estudos e investigações realizados em diferentes contextos nacionais na região latino-americana. (MORGENSTERN, 2010). São numerosos estudos que demonstram a perda de autonomia dos docentes pelos processos de massificação do ensino trazida pela expansão da escolaridade, o arrocho salarial imposto a esses trabalhadores combinado à deterioração das condições de trabalho, em muitos casos afetando a saúde dos trabalhadores, a crescente feminização do magistério, entre outros aspectos que foram ocorrendo nas últimas décadas do século passado. Algumas pesquisas têm demonstrado na atualidade a ocorrência de alto grau de intensificação do trabalho, os docentes assumindo novas funções e responsabilidades no contexto escolar, além da crescente pauperização desses trabalhadores e de seus alunos e as consequências diretas desses fatores sobre os resultados escolares'. Por tais razões, a questão da valorização docente no contexto brasileiro adquire centralidade na atualidade.

As condições de trabalho e de carreira e, especialmente, a remuneração oferecidas pelas redes públicas de educação básica no Brasil, têm tido efeito direto sobre a busca por essa profissão entre os jovens egressos do Ensino Médio que vão seguir seus estudos. Em estudo realizado pelo Instituto Nacional de Estudos e Pesquisas Educacionais (Inep), denominado "Quem quer ser professor no Brasil? $\bigcirc$ que o Enem nos diz"2 , com jovens de 17 a 20 anos que fizeram a prova do Exame Nacional do Ensino Médio - Enem em 2007, observou-se que $25 \%$ ainda não haviam escolhido, até aquele momento, a profissão que pretendiam seguir. Dos que já haviam feito sua escolha, a maioria optou por profissões da área de Ciências Biológicas e da Saúde, seguidas por profissões da área de Engenharias e Ciências Tecnológicas e da área de Ciências Humanas. Aqueles que escolheram a profissão de Professor da Educação Básica correspondem a apenas 5,2\% dos jovens. $\bigcirc$ baixo percentual de escolha pelos cursos de formação de professores indica um preocupante 
nível de atratividade da carreira que em um futuro próximo poderá trazer consequências graves.

Considerando que dos 2.045.350 docentes ${ }^{3}$ que atuam na educação básica na atualidade, 1.650.122 são mulheres e 885.008 do total têm idade superior a 41 anos e que o direito previdenciário assegura a possibilidade de aposentadoria especial com 25 anos de efetiva contribuição, a formação de nova geração de docentes no país deveria ser um imperativo.

Analisando o perfil dos que querem ser professores (5,2\%), o estudo conclui que os indivíduos com maior probabilidade de escolher o magistério - aqueles com 17 a 20 anos que realizaram o Enem 2007 e declararam a opção pela profissão de professor de educação básica - têm o seguinte perfil: são mulheres, estudaram sempre em escolas públicas, têm renda familiar de até dois salários mínimos e a mãe não completou o ensino médio. Os dados do estudo constituem, embora não tenha sido o propósito do tema, uma indicação do perfil socioeconômico dos candidatos ao magistério na educação básica.

No Brasil e em muitas partes do mundo, o magistério não está entre as profissões mais requisitadas nem entre os que já se ingressaram em cursos de formação de professores, pois para muitos este constitui sua segunda opção. (LEME, 2012 ). Como evidência dessa preocupação em outros contextos nacionais está o esforço de alguns organismos internacionais em produzir estudos sobre o problema, com especial destaque para a Organização para Cooperação e Desenvolvimento Econômico (OCDE).

$\bigcirc$ Relatório Talis, publicado em 2005, pela $\bigcirc C D E$, intitulado: "O papel crucial dos professores: atrair, formar e reter os professores de qualidade" tem influenciado enormemente políticas nacionais no sentido de buscar compreender o problema da baixa atratividade da profissão vinculando-o à formação docente. $\bigcirc$ estudo expressa a preocupação de atrair, capacitar e conservar os professores eficientes traduzindo bem o que no mundo vem sendo difundido, sobretudo pelos Organismos Internacionais, como Desenvolvimento Profissional Docente (DPD).

Observa-se uma centralidade às políticas docentes na última década pelos organismos internacionais, em especial a Organização das Nações Unidas para a Educação, a Ciência e a Cultura (UNESCO), a Organização dos Estados Ibero-americanos para a Educação, a Ciência e a Cultura (OEI) e a OCDE que têm atribuído maior ênfase à formação e à avaliação como 
fatores determinantes na melhoria da profissão docente e, consequentemente da educação, que aspectos relativos às condições de trabalho, carreira e salários.

\section{A crise da carreira docente e o recurso ao DPD}

A busca pela compreensão dos fatores que levam à melhoria da educação tem levado certas abordagens a colocar o professor como o principal responsável pela tarefa educativa e, consequentemente, por seus resultados, deslocando o foco das estruturas e das relações sociais que envolvem o contexto escolar. Por essa razão, a busca de solução acaba apontando sempre na perspectiva de encontrar bons professores lquase super-heróis, dependendo do contexto em que ensinam) para resolver os problemas da educação. $\bigcirc$ tema da atratividade docente da maneira como vem sendo pautado pela OCDE aponta a preocupação com a busca de "bons profissionais" para a educação, como se a solução fosse buscar professores eficazes, bem formados, capazes de neutralizar os demais fatores que influem diretamente sobre os resultados acadêmicos, tais como a origem social dos alunos e seu capital cultural, as condições de trabalho nas escolas, a gestão escolar, entre outros. Nessa perspectiva, acabam por atribuir grande centralidade ao professor e à sua formação.

A preocupação em articular políticas de formação às condições de profissionalização é resultante do acentuado peso dado à formação na definição e certificação da profissão, observado em várias áreas, mas especialmente na educação. O Relatório "Creating Effective Teaching and Learning Environments: First Results from TALIS", publicado pela OCDE, em 2009, traz um estudo comparativo das condições de trabalho e do ambiente de ensino e aprendizagem em escolas de 23 países. $\bigcirc$ Relatório atribui particular ênfase a questões como: até que ponto os professores se acham bem-sucedidos na forma como respondem aos desafios educacionais que enfrentam e até que ponto existe nas salas de aula um bom comportamento e um ambiente propício à aprendizagem, considerando o clima disciplinar da sala de aula? $\bigcirc$ estudo pretendeu realizar uma análise da avaliação do desempenho dos professores nos países pesquisados, concluindo que a formação profissional contínua dos professores é fator decisivo na melhoria das condições de ensino. 
As políticas de DPD aparecem assim no debate sobre a formação na agenda educativa global e regional nos últimos anos, como sinônimas às políticas de formação continuada ou em serviço, difundidas por meio de documentos produzidos por organismos internacionais. (FELDFEBER, 2010). Esses organismos têm conseguido difundir uma noção de DPD que envolve não só a busca pela formação continuada, mas, sobretudo, a responsabilização dos sujeitos por essa busca, como orientação para as políticas de formação docente em diferentes contextos nacionais.

As políticas de formação e DPD têm merecido significativo destaque nas últimas duas décadas em muitas partes do mundo. Buscando articular a formação continuada às necessidades de profissionalização dos docentes, tais políticas são apresentadas como requisito indispensável à melhoria da educação no sentido de atender as demandas para a educação do século XXI. As políticas de DPD fundamentam-se no paradigma da sociedade do conhecimento em que a educação ao longo da vida passa a ser um imperativo. (DELORS, 1998).

A retórica da sociedade do conhecimento, ainda que tenha sido assumida em grande medida pelos discursos expressos nos documentos e políticas 56 educativas oficiais no Brasil, tanto no governo de Fernando Henrique Cardoso quanto de Luiz Inácio Lula da Silva, curiosamente não adotou o DPD como um conceito que traduzisse suas proposições no que se refere à formação e profissão docente. De igual maneira, os sindicatos no Brasil tampouco têm utilizado o DPD como um conceito que expresse suas demandas por maior profissionalização.

Contudo, a despeito do termo DPD ser pouco ou quase nada mencionado nos documentos legais que se referem às políticas de formação e carreira docente, em muitos casos, converge na direção que apontam as tendências internacionais; apesar de em outros contextos nacionais na América Latina as políticas de DPD terem assumido caráter positivo como resposta à corrosão da profissionalização docente vivida nas reformas neoliberais dos anos 1990. A contradição presenciada nesse debate demonstra certa tendência à naturalização de termos que, a despeito de terem matrizes que se podem considerar de orientação liberal, são assimilados em sociedades que na atualidade experimentam regimes políticos mais democráticos e até mesmo progressistas de origem popular. Isso pode ser atribuído em certa medida a um vazio teórico-conceitual que acaba sendo preenchido por respostas prontas (ou fáceis?), 
muitas vezes superficiais e descontextualizadas, apresentadas por estudos produzidos em curto tempo, de alcance reduzido e muitas vezes sem qualquer empiria, ainda que em alguns casos assinados por consultores renomados no campo educativo.

Esse debate ganha maior relevância neste momento em que o Brasil enfrenta uma crescente demanda trazida pela expansão da obrigatoriedade escolar que tem compelido a uma significativa reestruturação da formação docente. Como já mencionado, o Brasil conta com cerca de dois milhões de professores que atuam na educação básica em todo o território nacional, dos quais, aproximadamente, $82 \%$ atuam na rede pública de ensino. De acordo com o mesmo censo, o contingente de alunos matriculados na educação básica - compreendendo suas três etapas: educação infantil, ensino fundamental e ensino médio e suas modalidades - é de 50.972.619, sendo que 43.053.942 destes estão na rede pública. Esse contingente tende a aumentar progressivamente. A ampliação da obrigatoriedade escolar coloca importantes desafios para as políticas de formação docente para a educação básica, sobretudo no que se refere à educação infantil e ensino médio. Na realidade, os desafios não são novos, somente se tornam mais urgentes, pois desde 1996, com a promulgação da Lei de Diretrizes e Bases da Educação Nacional (Lei n 9394 de 20 de dezembro de 1996), a exigência de se formar mais professores em nível superior no país para atender a expansão da educação básica já havia sido manifestada.

Onúmero de docentes que ałuam na educação básica sem possuir a habilitação específica tem sido objeto de preocupação constante nos últimos 15 anos. (RISTOFF, 2011 ). Foram muitas iniciativas no plano federal e dos estados no sentido de buscar oferecer formação em nível superior para os professores em efetivo exercício nas redes públicas. E o resultado dessas iniciativas não é desprezível, o número de professores com curso superior no Brasil cresceu significativamente após a promulgação da LDB n 9.394/96. A expansão da matrícula em educação básica nesse período foi acompanhada pela evolução do grau de instrução dos professores. Ao longo dos últimos quinze anos, a porcentagem de docentes com curso superior completo cresceu nas três etapas da educação básica. $\bigcirc$ avanço mais expressivo ocorreu entre os profissionais que atuam nos anos iniciais do ensino fundamental. Em 2001 , menos de um terço desses professores (27\%) tinha formação superior. Em 2010, essa porcentagem mais que dobrou, passando para 62,4\%. A 
educação infantil registrou a segunda evolução mais significativa, passando de $24,7 \%$ para $51,8 \%$ de graduados no período. Os dados são do Inep e abrangem escolas públicas e particulares.

Segundo a Associação Brasileira de Educação a Distância (Abed), a melhoria na titulação dos professores brasileiros foi içada por outro fenômeno educacional recente: a expansão da educação à distância (EAD) no país. Entre 2000 e 2008, a quantidade de alunos nessa modalidade, em cursos de graduação e pós-graduação lato-sensu, cresceu $45.000 \%$, passando de 1.758 para 786.718 matriculados. No mesmo período, o número de cursos reconhecidos pelo Ministério da Educação aumentou de 13 para $1.752^{5}$.

Assim, observa-se que as políticas de formação docente no Brasil têm adquirido relevância nas últimas décadas muito em razão da necessidade de responder às exigências de titulação ao conjunto dos professores que atuam nos estabelecimentos de educação básica e à perspectiva de demandas de novos profissionais para atender à expansão da obrigatoriedade escolar.

\section{8 carreira}

Considerada um dos pilares da valorização docente, a formação inicial e continuada tem sido objeto de disputa de diferentes segmentos sociais que atuam no campo educacional. Contudo, tais políticas têm tomado contornos bastante específicos envolvendo a profissionalização dos docentes que ałuam na educação básica pública, sendo compreendida como uma das exigências para a valorização docente, somadas à remuneração e às condições de trabalho e carreira.

A mobilização em torno da formação de professores, envolvendo universidades públicas e privadas, consórcios e diferentes arranjos institucionais, é acompanhada da enorme crença de que a formação é a estratégia fundamental para a melhoria da educação básica. Os argumentos são em geral provindos de uma mesma matriz que acredita que formando professores para uma atuação eficaz em sala de aula ${ }^{6}$ conseguirão superar as dificuldades de aprendizagem apresentadas por seus alunos e causadora do baixo desempenho dos mesmos. Trata-se de uma abordagem sobre o problema que isola fatores, acreditando que por meio do denominado "efeito sala de aula" se 
conseguirá elevar o nível de desempenho dos alunos até alcançar objetivos e metas previamente estabelecidos pelos gestores públicos. Esse tipo de análise deposita demasiado peso na capacidade que a escola tem por ela mesma de mudar o destino das pessoas, ignorando fatores estruturais que interferem diretamente nesse processo.

Apesar da centralidade que ocupam as políticas de formação no que concerne à questão docente no Brasil desde os anos 1990, somente mais recentemente assistiu-se no plano federal a tentativa de estruturação de uma política nacional de formação. $\bigcirc$ Decreto $n^{\circ}$ 6.755, de 29 de janeiro de 2009, institui a Política Nacional de Formação de Profissionais do Magistério da Educação Básica, estabelecendo as bases para a criação do Plano Nacional de Formação de Professores da Educação Básica (Parfor), no âmbito da Coordenação de Aperfeiçoamento de Pessoal de Nível Superior (CAPES). $\bigcirc$ Parfor é apresentado como resultado de um conjunto de ações do Ministério da Educação (MEC), em colaboração com as secretarias de educação dos estados e municípios e as instituições públicas de educação superior neles sediadas, para ministrar cursos superiores gratuitos e de qualidade a professores em exercício das escolas públicas sem formação adequada determinada pela LDB n 9394/96, expressando assim a preocupação em buscar garantir a formação em nível superior para os professores em exercício nas escolas de educação básica. Entretanto, o dispositivo legal presente na LDB n 9394/96, nos seus artigos 61 e 62, que estabelecia a exigência de formação em nível superior para atuação docente na educação básica sofreu alteração a partir das Leis 12.014 de 06 de agosto de 2009 e 12.796/2013, respectivamente. A Lei 12.014/2009 modifica a redação original do artigo 61 da LDB $n^{\circ}$ 9394/96, com a finalidade de discriminar as categorias de trabalhadores que se deve considerar profissionais da educação, estabelecendo, dando the nova redação, como se pode observar:

Art. 1\%: $\bigcirc$ art. 61 da Lei n9.394, de 20 de dezembro de 1996, passa a vigorar com a seguinte redação:

Art. 61 : Consideram-se profissionais da educação escolar básica os que, nela estando em efetivo exercício e tendo sido formados em cursos reconhecidos, são:

I - professores habilitados em nível médio ou superior para a docência na educação infantil e nos ensinos fundamental e médio (grifos meus); 
II - trabalhadores em educação portadores de diploma de pedagogia, com habilitação em administração, planejamento, supervisão, inspeção e orientação educacional, bem como com títulos de mestrado ou doutorado nas mesmas áreas;

III - trabalhadores em educação, portadores de diploma de curso técnico ou superior em área pedagógica ou afim.

Parágrafo único. A formação dos profissionais da educação, de modo a atender às especificidades do exercício de suas atividades, bem como aos objetivos das diferentes etapas e modalidades da educação básica, terá como fundamentos:

I - a presença de sólida formação básica, que propicie o conhecimento dos fundamentos científicos e sociais de suas competências de trabalho;

II - a associação entre teorias e práticas, mediante estágios supervisionados e capacitação em serviço. (grifos meus);

III - o aproveitamento da formação e experiências anteriores em instituições de ensino e em outras atividades. (BRASIL, 2009).

Já o artigo 62, alterado pela Lei 12.796 de abril deste ano, traz explicitamente a alteração em relação à exigência de formação, como se pode constatar a seguir:

Art. 62. A formação de docentes para atuar na educação básica far-se-á em nível superior, em curso de licenciatura, de graduação plena, em universidades e institutos superiores de educação, admitida, como formação mínima para o exercício do magistério na educação infantil e nos 5 (cinco) primeiros anos do ensino fundamental, a oferecida em nível médio na modalidade normal. (BRASIL, 2013, grifos meus).

Essas duas leis expressam uma tendência recente que tem marcado o debate sobre a formação docente em relação ao nível de escolaridade exigido para se atuar na educação básica no país. Tais mudanças na norma legal refletem posições políticas que têm defendido interesses diversos no debate sobre a formação docente. Por um lado, observa-se que a defesa da formação inicial em nível superior tem sido há décadas defendida como um princípio para os que lutam pela profissionalização docente. Compreendendo a formação como determinante da profissão, as entidades acadêmicas têm defendido por meio 
de suas representações a formação em nível superior, em cursos presenciais e preferencialmente em universidades públicas.

Com as mudanças trazidas pelas referidas leis, passa a ser admitida como norma uma condição que antes era exceção, ou seja, a formação em nível médio para os profissionais que irão atuar na educação básica nos seus anos iniciais. No caso específico da educação infantil, que agora vive expressiva expansão resultante da já mencionada Emenda Constitucional n 59 de 11 de novembro de 2009, a admissão da formação em nível médio determina exigência menor de qualificação justamente para os que vão atuar na etapa primeira e talvez mais importante da educação. Essas mudanças terminam por reforçar a formação normalista de nível médio para atuar na educação da infância e, dessa maneira, contribuem indiretamente para o enfraquecimento dessa etapa como lugar da profissão docente.

Só se compreende essa mudança no âmbito legal se forem observadas as ações levadas a termo pelo movimento sindical docente que resultaram na Lei do Piso Salarial Nacional para os Profissionais da Educação ${ }^{7}$ e que passou a exigir a definição de quais eram esses profissionais. $\bigcirc$ rebaixamento da exigência de escolaridade em relação ao que havia sido estabelecido em lei anterior pode ser compreendido como uma reação corporativa dos trabalhadores da educação organizados economicamente em um mesmo sindicato, no sentido de protegerem e garantirem os direitos daqueles que já atuam em redes públicas nessa condição. Por outro lado, é possível que a pressão exercida pelos gestores municipais também tenha influenciado essas mudanças, tendo em vista o grande desafio que se deparam de garantir a oferta na educação infantil a partir dos 4 anos, trazida pela expansão da obrigatoriedade escolar e o dever de cumprir a lei do PSPN.

\section{Formação como condição para a profissionalização}

A noção de profissionalização aplicada à educação sempre foi ambígua. De acordo com Savoie (2009), o uso do termo profissionalização na educação sempre esteve vinculado ao quadro conceitual da sociologia americana das profissões, em que a profissionalização supõe não somente a prática do ofício em tempo pleno, mas também um estatuto legal que reconhece a qualificação dos seus membros como uma formação específica e a 
existência de associações profissionais. Ainda de acordo com o mesmo autor, essa profissionalização se traduz pela constituição de um patrimônio cognitivo e deontológico comum, sendo assim, as noções de profissionalidade e profissionalização são impostas no domínio da formação docente fazendo passar do plano social ao das práticas profissionais e pedagógicas.

Tal noção de profissionalização está imbricada aos processos de formação, sendo então a profissionalização dependente da formação. O que constitui o grupo ou corpo profissional é justamente o sentimento de pertencimento comum que começa mesmo antes do ingresso no local de trabalho. Contudo, esse sentimento de pertencimento comum encontra alguns obstáculos no domínio da educação, por exemplo, a fisionomia dos docentes do ensino médio é bastante distinta daquela dos que atuam nos anos iniciais do ensino fundamental e mais ainda na educação infantil.

Entretanto, para se discutir a formação compreendendo-a como base do processo constitutivo da profissionalização, é necessário considerar aspectos relativos à identidade docente. É vasta a discussão sobre a identidade docente na atualidade, são muitos os estudos que tratam desse tema em distintas realidades ${ }^{8}$. No Brasil, são muitos os fatores que têm levado à discussão 62 de uma identidade docente engendrada pelos recentes processos de reforma educacional que trouxeram a descentralização administrativa, pedagógica e financeira para o âmbito escolar. A ênfase no trabalho coletivo, a instituição legal da gestão democrática nas escolas públicas e a flexibilidade curricular foram fatores que resultaram em maior autonomia docente ao mesmo tempo em que têm levado à intensificação do trabalho e maior responsabilização pelo sucesso e fracasso escolar. (OLIVEIRA, 2004; 2007; 2009; 2010).

Todavia, é a partir da inclusão da Educação Infantil definitivamente como uma etapa da educação básica ${ }^{9}$, compreendendo inclusive as creches, ou seja, a educação das crianças de $\mathrm{O}$ a 3 anos, é que a questão da identidade docente será posta no centro do sistema. Tal medida obriga a que se pense o profissional da educação básica em um contexto e rol mais complexo de atividades, responsabilidades e competências que envolvem desde o cuidado e a atenção no processo educativo presentes na educação infantil até a fragmentação disciplinar própria do ensino médio. $\bigcirc$ contraste entre essas duas pontas da educação básica é tão grande que dificulta pensar a possibilidade de um grupo homogêneo que possa constituir-se em um corpo 
profissional. Tais dificuldades refletem-se na definição dos currículos e diretrizes para a formação de professores.

Dentre esses desafios, a formação dos profissionais que atuam na educação infantil apresenta-se como o mais urgente e polêmico. As especificidades da Educação Infantil, envolvendo no processo educativo o cuidado e a atenção, conforme já mencionado, acrescidas ainda à informalidade presente nos processos de trabalho nas creches e pré-escolas, fruto do descaso de séculos que essa etapa da educação conviveu, obrigam a revisão dos padrões usuais de formação docente que têm na figura tradicional do professor que ministra uma disciplina o modelo de profissional a ser perseguido.

Por um lado, observa-se a resistência (ou mesmo dificuldades) em se conceber a atuação docente distinta da tradicional de base disciplinar e, por outro, a ideia vigente no senso comum de que para cuidar de crianças pequenas não é necessário ter formação específica, sendo algo natural da gênese feminina o cuidado e atenção. Não é sem razão que a feminização do magistério é muito mais presente na educação infantil e que à medida que se avança na educação básica, aumenta a presença do sexo masculino entre os profissionais.

São muitos os desafios à formação inicial docente para atuar na educação básica presentes na atualidade, o que exige discutir profundamente e reconhecer as identidades visíveis nesse suposto grupo homogêneo, que na realidade apresenta distinções ignoradas. Conhecer essas distinções, os saberes e fazeres desses profissionais, os vínculos e sentimentos de pertencimento institucional, as exigências que lhes são postas, as responsabilidades e constrangimentos aos quais estão expostos são condições essenciais para se pensar a adequação curricular da formação que deverá promover a porta de entrada para o exercício profissional docente. Porém, a formação não é suficiente para definir a profissionalização docente, é necessário considerar outros fatores que interferem na identidade profissional dos que atuam na educação básica.

\section{A formação continuada e a profissionalização docente}

Se entre os elementos constitutivos da profissionalização docente o critério da formação inicial específica é indispensável, a formação continuada 
tem sido cada vez mais reclamada como uma condição para o pleno exercício da docência. As políticas de DPD aparecem nesse contexto como uma resposta aos processos de formação e profissionalização, insistindo na necessidade de os professores buscarem permanentemente melhorias no seu desempenho, na sua atuação. Apesar de em alguns casos a noção de desenvolvimento profissional estar associada à possibilidade de progresso na vida profissional, levando em consideração outros fatores para além da formação continuada: salário, condições de trabalho, carreira, o peso atribuído à formação é preponderante. (OLIVEIRA, 2010).

A formação aparece na literatura difusora da noção de DPD como condição de tal desenvolvimento, como um projeto coletivo, colaborativo e crítico-reflexivo, em que o desenvolvimento profissional é ao mesmo tempo desenvolvimento institucional. (RAMALHO, GAUTHIER, NUNEZ, 2004; GONZALES TORRES, 2003). Esse termo aparece como um desenvolvimento ou assimilação do conceito de sujeito reflexivo moderno ${ }^{10}$.

A formação continuada é apresentada como sinônimo de desenvolvimento profissional ao longo da vida, único fator capaz de justificar e pôr em movimento os outros componentes que conduzem à profissionalização. A 64 construção da profissão docente estaria assim dada, sobretudo, pela formação concebida como a possibilidade de aprendizagem permanente. Trata-se de uma abordagem normativa, que estabelece o desenvolvimento profissional e institucional como faces da mesma moeda e que atribui à consciência do profissional a possibilidade de mudança ética na educação. Os professores são, em última instância, os responsáveis por seu desenvolvimento profissional, que deve ser tomado como um dever e obrigação para a melhoria da educação em geral. (OLIVEIRA, 2009; 2010).

peso atribuído à formação, sobretudo a acadêmica, acaba por defini-la como o principal critério determinante da profissionalização, desprezando, muitas vezes, o conhecimento obtido na experiência, na prática concreta por esses profissionais. Segundo Perrenoud (2002), a formação é o caminho para a profissionalização, pois é ela que permitirá o desenvolvimento da capacidade reflexiva desses profissionais. $\bigcirc$ apelo do autor à noção de competência como a capacidade de o profissional lidar de forma prática, segura e dinâmica com as novas exigências que se the apresentam no trabalho parece desconsiderar as condições objetivas desse trabalho e desses trabaIhadores. A noção de competências está intimamente ligada à capacidade 
dos indivíduos de se adequarem a novas situações e a resolverem problemas que possam enfrentar na sua realidade de trabalho. Contudo, essa noção traz em si a ideia de obtenção de sucesso, de eficiência, ser competente, pois está centrada na busca de mobilização das subjetividades dos trabalhadores, do seu envolvimento e compromisso com os objetivos da instituição, com as demandas da comunidade, do sistema e dos alunos. Essas políticas apelam para o desempenho do corpo docente: o professor é o responsável pelo sucesso ou fracasso do sistema medido em geral pelo desempenho dos alunos. Ao fazerem essa defesa em um contexto marcado por condições desiguais e pouco propícias à realização profissional, os argumentos acabam por traduzir-se em retórica que obscurece (ou nega) as contradições próprias das relações de trabalho presentes no ambiente escolar e terminam por depositar sobre os ombros dos docentes a responsabilidade pelos resultados escolares.

\section{A formação como condição para a valorização docente}

Em recente survey ${ }^{1}$ realizado em sete estados do Brasil, tendo como objetivo analisar o trabalho docente nas suas dimensões constitutivas, identificando seus atores, o que fazem e em que condições realizam o trabalho nas escolas de Educação Básica de redes públicas municipais e estaduais e instituições conveniadas na educação infantil, foi possível observar que os dados referentes aos elementos constitutivos da valorização docente - formação, remuneração e condições de trabalho e carreira - são preocupantes e que os vínculos entre a formação e remuneração apresentam correlação significativa.

A partir de 8.795 entrevistas com docentes em unidades educacionais (creches e escolas) em sete estados brasileiros (Minas Gerais, Espírito Santo, Goiás, Rio Grande do Norte, Pará, Paraná e Santa Catarina), utilizando-se de um questionário com 85 questões e que contém 319 variáveis, foi traçado o perfil socioeconômico e cultural dos docentes em exercício na Educação Básica no Brasil. Buscou-se ainda conhecer a divisão técnica do trabalho nas unidades educacionais, a emergência de novos postos de trabalho, cargos e funções derivados de exigências e atribuições que emergiram nos últimos anos. Procurou-se também conhecer as atividades desenvolvidas pelos docentes e em que condições de trabalho: os meios físicos, os equipamentos disponíveis, os recursos pedagógicos, entre outros fatores que interferem diretamente na 
realização do trabalho docente. Foram coletadas informações sobre a formação inicial e continuada dos docentes, o acesso à literatura específica das áreas de atuação, às tecnologias e a outros bens culturais para o desenvolvimento de seu trabalho. As formas de contratação, as condições salariais e de carreira nas diferentes redes de ensino foram também objeto de investigação.

Foram considerados sujeitos docentes nessa pesquisa os trabalhadores que realizam atividades que se relacionam diretamente com o processo educativo, sendo compreendidos aí os professores e outros profissionais que exercem atividade de docência. Observou-se uma grande variedade de nomenclatura para definir o profissional que atua na educação infantil. Os dados obtidos sobre a formação inicial e continuada ajudam a compreender o peso que exercem na condição profissional dos docentes e em que medida eles são determinantes das remunerações.

Os dados relativos à formação inicial dos 8.795 respondentes indicaram que: 0,1 18\% possuem o Ensino Fundamental incompleto; 0,27\% Ensino Fundamental completo; 0,72\% Ensino Médio incompleto; 14,82\% Ensino Médio completo; 32,02\% curso superior em nível de Graduação e 51,99\% algum curso de Pós-Graduação. Considerando para esta análise apenas os 66 docentes que possuem algum curso de pós-graduação e buscando conhecer sua distribuição entre os sete estados, observa-se um percentual maior de professores com titulação mais alta no estado do Espírito Santo $(73,6 \%)$ e em Santa Catarina $(66,8 \%)$. Entre os docentes que ocupam outros cargos, o Pará aparece em primeiro lugar $(51,6 \%)$ seguido por Santa Catarina (51,3\%). O Rio Grande do Norte apresentou os percentuais mais baixos de docentes com cursos de pós-graduação, tanto para professores $(37,4 \%)$ quanto para as demais funções $(37,6 \%)$.

Quando se observa os docentes com maior titulação por rede de ensino, constata-se que o percentual de professores com cursos de pós-graduação é de 53,4\% nas redes municipais e 57\% nas redes estaduais. Entre os docentes com demais funções, chama a atenção o alto percentual nas redes estaduais, 59,8\%. Nas redes municipais, esse percentual é de 40\%. Nas redes conveniadas, os valores ficaram bem abaixo das redes públicas, sendo $25,8 \%$ para professores e 16,6\% para as demais funções.

Já quando se põe em evidência os dados por etapas de ensino, observa-se um percentual maior de docentes com mais alta titulação no Ensino 
Fundamental e Ensino Médio em relação à Educação Infantil. $\bigcirc$ percentual de professores da Educação Infantil com curso de pós-graduação é de 42\%, enquanto para o Ensino Fundamental é de $54,8 \%$ e de $58,8 \%$ para o Ensino Médio. Nas demais funções, esses valores são ainda mais discrepantes, sendo 19,2\% na Educação Infantil, 52,9\% no Ensino Fundamental e 60,4\% no Ensino Médio.

Quando se confronta os dados de formação com aqueles relativos à carreira e condições de trabalho e a remuneração, observa-se que, apesar de apresentarem na sua maioria a formação compatível para o exercício de suas funções, 84,01\% possuem curso superior, sendo que a maioria investiu na educação continuada em nível de pós-graduação, 51,99\%, mas tal investimento não vem acompanhado percentualmente dos dados relativos à carreira. Do total dos respondentes, 46,2\% afirmam que não estão contemplados por um plano de carreira.

Em relação aos ganhos salariais, observa-se uma concentração maior de professores com titulação menor nas faixas salariais mais baixas, em que $39,2 \%$ ganham entre um e dois salários mínimos. Se considerarmos somente as três faixas de rendimentos mais baixos (até três salários mínimos), vemos que mais de 70\% dos docentes sem curso de pós-graduação encontram-se nessas faixas, enquanto para os docentes com pós-graduação esse percentual fica pouco acima dos $50 \%$.

Esse mesmo comportamento é observado de forma mais acentuada entre os docentes que ocupam demais funções. A maior concentração de docentes sem cursos de pós-graduação encontra-se nas três faixas de rendimentos mais baixos, sendo que mais de $80 \%$ dos docentes de menor titulação ganham até três salários mínimos. Entre os docentes com titulação maior, esse percentual é de $44 \%$.

Constata-se, pela apreciação dos dados, que, mesmo em níveis muito baixos e insatisfatórios, os rendimentos dos docentes tendem a acompanhar os níveis de formação, ou seja, quanto mais titulado maior a remuneração, ainda que esta seja abaixo do que percebem outros profissionais com mesma escolaridade. Importante argumento para justificar a defesa de educação inicial em nível superior para todos os docentes.

Mesmo que possamos considerar a realização de estudos em nível de pós-graduação como formação continuada desejável, a Capes tem investido 
nos últimos anos na criação e fomento a programas de mestrado profissional dirigidos aos professores de educação básica em redes públicas, a formação em serviço, por meio de atividades esporádicas e eventuais, que tem sido predominantemente apontada pelos docentes quando perguntados sobre o acesso que têm a esse tipo de educação. Em relação às atividades de formação continuada assim compreendidas, observa-se um percentual baixo de docentes que as realizaram, seja entre os professores $(16,4 \%)$, seja entre os docentes que desempenham outras funções (14,4\%).

Ao relacionar o fato de ter realizado atividades de formação continuada e os ganhos salariais, observa-se que não há uma relação direta de ganho, diferentemente do que ocorre com a formação inicial, conforme comentado. A distribuição que se apresenta exibe percentuais muito semelhantes entre as faixas salariais para os docentes que realizaram ou não atividades desse tipo. $\bigcirc$ que nos leva a inferir que tais atividades têm pouco impacto na remuneração dos docentes.

De todo modo, a formação continuada com tais características parece ter ainda menos efeitos entre os professores que os demais docentes. No caso dos docentes das demais funções, apesar de se observar um comportamento 68 semelhante, fica mais clara uma leve diferença. Os docentes que realizaram atividades de formação continuada apresentam um percentual um pouco maior em algumas faixas de salários mais altas, como na faixa entre quatro e cinco salários mínimos, por exemplo, em que o percentual dos que realizaram as atividades é de 10,4\% contra 8, 1\% dos que não realizaram. Essa variação pode ser explicada pela presença dos especialistas e dirigentes escolares que figuram nessa faixa. Um comportamento inverso é observado na faixa salarial mais baixa, na qual o percentual dos que realizaram tais atividades é de 10,8\% enquanto os que não realizaram atingem 18,2\%.

A participação em atividades de formação continuada aparece em terceiro lugar entre os aspectos mais valorizados nos planos de cargos e salários tanto dos professores quanto dos docentes que ocupam outras funções. A titulação aparece em primeiro lugar, seguida pelo tempo de serviço. O percentual de docentes que destacaram a participação em atividades de formação continuada como um aspecto valorizado no plano de cargos e salários é de $21,1 \%$ para os professores e $20,2 \%$ para os docentes que ocupam outras funções. 


\section{Comentários finais}

Dentre as políticas que na atualidade buscam responder às demandas por maior valorização docente, destacam-se as políticas de formação. Tais políticas têm adquirido relevância em razão da necessidade de responder às exigências de titulação ao conjunto dos professores que atuam nas escolas de educação básica no país. Desde a promulgação da LDB n 9394/96, o grau de instrução dos professores brasileiros tem aumentado significativamente. Apesar disso, a legislação educacional foi alterada no sentido de permitir que o que antes era exceção, a formação em nível médio, passasse a ser a regra. As mudanças mais recentes na legislação brasileira apontam no sentido de um retrocesso nas conquistas, pelo menos no plano legal, obtidas em décadas anteriores.

Considerada um dos pilares da valorização docente, a formação inicial e continuada tem sido objeto de disputa de diferentes segmentos. Tais políticas sofrem influência da agenda educacional global e regional que tem trazido o apelo ao DPD que depositam na formação expressiva centralidade. As políticas de DPD podem promover o deslocamento das demandas de profissionalização centradas na carreira e condições de trabalho e na remuneração para um modelo de responsabilização dos docentes por sua formação, sobretudo a continuada, como forma de crescimento individual e profissional.

Com base na análise de dados produzidos pelo survey (TDEBBGESTRADO/UFMG), observou-se que essa tendência é pouco presente entre os respondentes. Constata-se com base nesses dados que a correlação entre a formação inicial (titulação) e a remuneração é significativa, ao passo que a formação continuada não apresenta correlação segura. Tais evidências podem contribuir no reforço à formação inicial em nível superior como importante fator de valorização direta, resultando em maior remuneração, ao mesmo tempo em que indicam a necessidade de se repensar políticas de formação continuadas.

É importante ainda salientar que a crise que enfrenta a carreira docente exige que medidas efetivas de reforço à carreira no sentido tanto das formas de ingresso quanto de permanência devem pressupor melhores condições de trabalho e de remuneração. 


\section{Notas}

1 Parte dos argumentos aqui desenvolvidos foi apresentada em uma mesa redonda intitulada Políticas de Formação e Desenvolvimento Profissional Docente: da intenção às práticas, que teve lugar no XX Endipe, realizado em 2012, em Campinas.

2 Oliveira e Vieira (2010), Tenti Fanfani (2005).

3 Publicado no Boletim on-line do Inep "Na Medida", setembro de 2009. Disponível em: www. inep.gov.br. Consulta em: 8 maio 2013.

4 Censo Escolar 2011. Disponível em http://download.inep.gov.br/educacao_basica/censo_ escolar/resumos_tecnicos/resumo_tecnico_censo_educacao_basica_2011.pdf. Sinopse atualizada em 12/06/2013.

5 http://www.gazetadopovo.com.br/vidaecidadania/conteudo. phtmleid=1 197626>. Acesso em: 30 nov. 2012.

6 Sobre o conceito "efeito sala de aula", ver: Bressoux (2003).

7 BRASIL. Lei n ${ }^{\circ} 11.738$, de 16 de julho de 2008. Regulamenta a alínea "e" do inciso Ill do caput do artigo 60 do Ato das Disposições Constitucionais Transitórias, para instituir o piso salarial profissional nacional para os profissionais do magistério público da educação básica. Brasília/ DF: Congresso Nacional, 2008.

8 Lessard, Dubar, Tardif e Lessard, Demailly, Medina \& kelly (2001), entre outros.

9 Refiro-me a duas medidas decisivas para a ampliação da oferta pública da educação infantil e que são políticas recentes: o Fundo de Manutenção e Desenvolvimento da Educação Básica e de Valorização dos Profissionais da Educação (FUNDEB) contemplando esta etapa da educação básica, portanto, garantindo o financiamento da educação de 0 a 5 anos e a EC n 59 de 2009 que amplia a obrigatoriedade escolar para o intervalo de 4 a 17 anos.

10 Para o conceito de sujeito reflexivo moderno, ver: Giddens (1 997) e Domingues (2003).

11 Pesquisa "Trabalho Docente na Educação Básica no Brasil" que contou com apoio do Ministério da Educação - MEC, em projeto institucional de cooperação técnica com a Secretaria de Educação Básica - SEB. O trabalho foi realizado em conjunto com oito grupos de pesquisa dos sete estados pesquisados, a saber: GESTRADO/UFMG, GESTRADO/UFPA, GETEPE/UFRN, NEDESC/UFG, NEPE/UFES, NUPE/UFPR, GEDUC/UEM-PR, GEPETO/UFSC.

\section{Referências}

BARROSO, João. A utilização do conhecimento em política: o caso da gestão escolar em Portugal. Educação \& Sociedade, Campinas, v. 30, n. 109, p. 987-1007, set./dez. 2009. 
BRASIL. Lei n 9.394 de 20 de dezembro de 1996. Estabelece as diretrizes e bases da educação nacional. Diário Oficial [da] República Federativa do Brasil, Poder Executivo, Brasilia, DF, 20 dez. 1996.

Lei $n^{0} 11.738$, de 16 de julho de 2008. Institui o piso salarial profissional nacional para os profissionais do magistério público da educação básica. Diário Oficial [da] República Federativa do Brasil, Poder Executivo, Brasília, DF, 16 jul. 2008.

Emenda Constitucional n 59, de 11 de novembro de 2009. Modifica a redação do artigo 76 do Ato das Disposições Constitucionais Transitórias e dá outras providências Diário Oficial [da] República Federativa do Brasil, Poder Executivo, Brasília, DF, 11 jan. 2009.

Resolução n², de 28 de maio de 2009. Fixa as Diretrizes Nacionais para os Planos de Carreira e Remuneração dos Profissionais do Magistério da Educação Básica Pública. Diário Oficial [da] República Federativa do Brasil, Poder Executivo, Brasília, DF, 28 maio. 2009

Lei $n^{\circ} 12.014$ de 06 de agosto de 2009 descrimina as categorias de trabalhadores que se devem considerar profissionais da educação. Diário Oficial [da] República Federativa do Brasil, Poder Executivo, Brasília, DF, O6 ago. 2009.

BRESSOUX, Pascal. As pesquisas sobre o efeito-escola e o efeito-professor. Educação em Revista, Belo Horizonte, n. 38, p. 17-86, dez. 2003.

DELORS, Jacques. Educação: um tesouro a descobrir. São Paulo: Cortez; Brasília: MEC/ UNESCO, 1998.

DOMINGUES, José Maurício. Ensaios de sociologia. Belo Horizonte: Editora UFMG, 2003.

FELDFEBER, Myriam. De la profesionalización al desarollo profesional: algunas notas para pensar cãs políticas de formación docente. In: OLIVEIRA, Dalila Andrade; FELDFEBER, Myriam (Compiladoras). Nuevas regulaciones educativas em America Latina: políticas y procesos Del trabajo docente. Lima: Fondo Editorial UCH, 2010. p. 81-108.

GIDDENS, Anthony. Modernidade e identidade pessoal. 2. ed. Oeiras/Portugal: Celta Editora, 1997.

GONZALES TORRES, María Carmen. Claves para favorecer la motivación de los profesores ante los retos educativos actuales. Estudios, n. 5, p. 62, 2003. 
LEME, Luciana França. Atratividade do magistério para a educação básica: estudo com ingressantes de cursos superiores da USP. 2012. Dissertação (Mestrado em Educação) Programa de Pós-Graduação em Educação, Universidade de São Paulo, São Paulo, 2012.

LESSARD, Claude. Regulação múltipla e autonomia profissional dos professores: comparação entre o Quebec e o Canadá. Educação em Revista, Belo Horizonte, n. 44, dez. 2006.

LESSARD, Claude \& TARDIF, Maurice. Les transformations actuelles de l'enseignement: trois scénarios possibles dans l'évolution de la profession enseignante? In: LESSARD, Claude. \& TARDIF, Maurice. La profession d'enseignant aujourd'hui: évolutions, perspectives et enjeux internationaux. Montréal/Canadá: La Presses de L'Université Laval, 2004.

MAROY, Christian. Em direção a uma regulação pós-burocrática dos sistemas de ensino na Europa? In: OLIVEIRA, Dalila Andrade; DUARTE, Adriana. Políticas públicas e educação: regulação e conhecimento. Belo Horizonte: Fino Traço, 2011.

MEDINA, S.A.; KELLY, E.P. Professionnalisme et procés de formation: I'expérience latino-américaine. Éducation et Sociétés, Paris, v. 2, n. 6, 2001.

MORGENSTERN, Sara. Professor/docente. In: OLIVEIRA, Dalila Andrade; DUARTE,

72 Adriana Cancella; VIEIRA, Lívia Fraga. Dicionário: trabalho, profissão e condição docente. Belo Horizonte: UFMG/Faculdade de Educação, 2010. 1. CD-ROM.

NÓVOA, Antonio. Os professores e a história da sua vida. In: NÓVOA, Antonio (Org.). Vida de professores. 2. ed. Porto: Porto Editora, 2000.

OLIVEIRA, Dalila Andrade. A reestrutaração do trabalho docente: Precarização e Flexibilização. Educação \& Sociedade, Campinas, v. 25, n. 89, p. $1127-1144$, set./ dez. 2004.

OLIVEIRA, Dalila Andrade. Política Educacional a re-estruturação do trabalho docente: reflexões sobre o contexto latino-americano. Educação \& Sociedade, Campinas, v. 28 n. 99, p. 355-375, maio/ago. 2007.

OLIVEIRA, Dalila Andrade (Org.). Gestão democrática da educação: desafios contemporâneos. 9. ed. Petrópolis: Editora Vozes, 2009.

OlIVEIRA, Dalila Andrade; VIEIRA, Lívia Maria Fraga. Trabalho docente na educação básica no Brasil: resultados de pesquisa. Belo Horizonte: GESTRADO/ UFMG, 2010. Disponível em: <www.trabalhodocente.net.br>. Acesso em: 11 maio 2013. 
OLIVEIRA, Dalila Andrade. A nova regulação de forças no interior da escola: carreira, formação e avaliação docente. Revista Brasileira de Política e Administração da Educação, Recife, v. 27, n. 1, p. 25-38, jan./abr. 2011.

OLIVEIRA, Dalila Andrade; FELDFEBER, Myriam. Novas e velhas formas de regulação dos sistemas educativos no Brasil e na Argentina. In: OLIVEIRA, Dalila Andrade; PINI, Mónica Eva; FELDFEBER, Myriam (Org.). Políticas educacionais e trabalho docente: perspectiva comparada. Belo Horizonte: Fino Traço, 2011.

PEREZ GOMEZ, Angel. Qualidade do ensino e desenvolvimento profissional do docente como intelectual reflexivo. Motriz, Rio Claro, v. 3, n. 1, 1997.

PERRENOUD, Philippe. A prática reflexiva no ofício de professor: profissionalização e razão pedagógica. Porto Alegre: Artmed, 2002.

RAMALHO, Betania Leite; GAUTHIER, Clermont; NUNEZ, Isaro Beltrán. Formar o professor, profissionalizar o ensino: perspectivas e desafíos. 2. ed. Porto Alegre: Sulinas, 2004.

RAYOU, Patrick. Épreuves d'aujourd'hui et metier de demain. Education \& Sociétés, Paris, Bruxelles: De Boeck \& Larcier, n. 23 (1), p. 5-13, 2009.

Ristoff, Dilvo. Construindo outra educação: tendências e desafios da educação brasileira. Florianópolis: Insular, 2011.

RODRIGUES, Maria de Lurdes. Sociologia das profissões. Oeiras/Portugal: Celta Editora, 2002.

SAVOIE, Philippe. Aux origines de la professionnalisation? La gênese Du corps enseignant secondaire français. Education \& Sociétés, Paris, Bruxelles: De Boeck \& Larcier, n. 23, v. 1, p. 5-13, 2009.

TENTI FANFANI, E. La condición docente. Siglo Veintiuno Editores: Buenos Aires, 2005. 


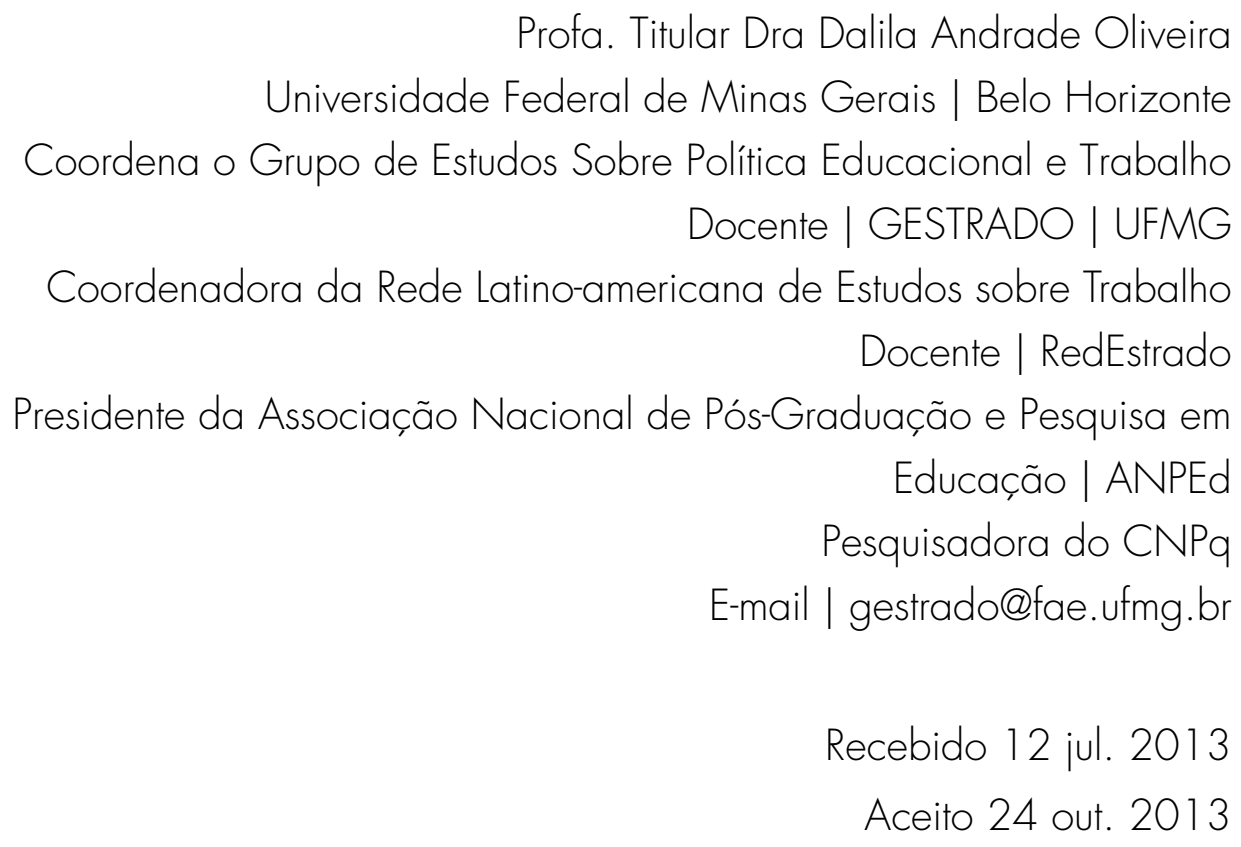

